\title{
Trade Wars and Trade Talks
}

\section{Citation}

Grossman, Gene M., and Elhanan Helpman. 1995. Trade wars and trade talks. Journal of Political Economy 103(4): 675-708.

\section{Published Version}

doi:10.1086/261999

\section{Permanent link}

http://nrs.harvard.edu/urn-3:HUL.InstRepos:3450062

\section{Terms of Use}

This article was downloaded from Harvard University's DASH repository, and is made available under the terms and conditions applicable to Other Posted Material, as set forth at http:// nrs.harvard.edu/urn-3:HUL.InstRepos:dash.current.terms-of-use\#LAA

\section{Share Your Story}

The Harvard community has made this article openly available.

Please share how this access benefits you. Submit a story.

Accessibility 


\title{
Trade Wars and Trade Talks
}

\section{Gene M. Grossman}

Princeton University

\section{Elhanan Helpman}

Tel Aviv University and Canadian Institute for Advanced Research

\begin{abstract}
When governments meet in the international arena, their actions reflect the political situations at home. Previous studies of trade relations have focused on governments that are immune from political pressures and that act as benevolent servants of the public interest. Here we introduce domestic politics into the analysis of international economic relations. We study the interactions between national leaders who are concerned with both providing a high standard of living to the general electorate and collecting campaign contributions from special-interest groups. Our analysis sheds light on the determinants of the structure of protection in noncooperative and cooperative policy equilibria.
\end{abstract}

\section{Introduction}

Recent events have highlighted the extent to which domestic politics condition international economic relations. Special-interest groups were visible and vocal in the weeks and years leading up to the Uruguay Round trade pact and the North American Free Trade Agreement. Similarly, industry representatives have been active participants in the ongoing trade conflict between the United States and Japan. There can be little doubt that interest groups have influenced these and other policy outcomes.

We thank the National Science Foundation and the U.S.-Israel Binational Science Foundation for financial support. Grossman also thanks the John S. Guggenheim Memorial Foundation, the Sumitomo Bank Fund, the Daiwa Bank Fund, and the Center of International Studies at Princeton University. 
In the political science literature, "statist" theories have dominated recent analysis of foreign economic policy (see Cowhey 1990). Such theories cast an elite group of executive branch institutions and officials as relatively independent players in the international arena, setting policies to serve national objectives (such as balance-of-power diplomacy) while making only occasional and minimal concessions to domestic political groups. This approach has its counterpart in the economics literature on trade relations, which too has focused on the actions and interactions of autonomous governments. In his seminal paper on "Optimum Tariffs and Retaliation" (1954), Harry Johnson showed how policy interdependence between governments could be modeled as a noncooperative equilibrium of a two-country tariff game (see also Kuga 1973; Riezman 1982; Kennan and Riezman 1988). Mayer (1981) and Riezman (1982) took a similar approach to negotiated trade agreements, viewing them as equilibrium outcomes to two-government bargaining games. While these authors surely are to be commended for emphasizing the international interactions that feature prominently in foreign policy determination, one cannot help but wonder whether their analyses capture the "true" objectives of real-world governments. In every case, the author has cast the government as a benevolent servant of the national interest.

It is now commonplace to view trade policy as an outgrowth of a political process that does not necessarily give rise to aggregate welfare maximization. A growing literature on endogenous policy formation treats interest groups (and sometimes voters) as participants in a competition for political favors, which are meted out by politicians serving their own selfish interests. However, this literature has focused exclusively on the case of a small or isolated country, one that sets trade policy without regard to the extant policies and possible reactions of its trade partners.

In this paper we develop a formal framework capable of capturing both strategic interaction between interest groups and politicians in the domestic arena and strategic interaction between governments in the international arena. In doing so, we follow the path suggested by Putnam (1988), who argued that international relations are best seen as just such a "two-level game." We study both noncooperative and cooperative tariff-setting games in a context in which domestic politics determine international objectives. Our goal is to understand how the political climate in one country conditions policy outcomes in another, and how domestic political pressures on politicians condition their relations with foreign counterparts. ${ }^{1}$

\footnotetext{
${ }^{1}$ Hillman and Moser (1995) also view trade policies as the outgrowth of interactions between politically motivated governments. Their analysis differs from ours inasmuch
} 
In Section II, we outline our model and discuss its relation to the existing literature. Section III spells out the formal assumptions of the model and the nature of a political equilibrium. In Sections IV and V, we study two-country policy games, assuming first that governments set their policies noncooperatively and then that they engage in international negotiations. Section VI compares the predictions of our model with some of the findings in the empirical literature.

\section{Model Outline and Relation to the Literature}

In democracies, trade policies are set by elected representatives. Because the public typically is less than fully informed about trade issues and because most elections cover many issues, these representatives need not always select policies that maximize the welfare of the median voter. Other policies may better serve the politicians' goal of being reelected and any further objectives they may have. The literature on trade policy formation studies the choices made by elected representatives who may receive financial and other inducements from special-interest lobby groups.

One strand of literature began with Brock and Magee (1978) and is most fully articulated in Magee, Brock, and Young (1989). They consider an election between two parties representing protectionist and free-trade interests. Prior to the election, each party commits to a platform specifying the trade policy it would carry out if elected. Then, seeing these platforms, lobby groups representing capital (which would benefit from free trade) and labor (which would benefit from high tariffs) make campaign contributions to the respective parties championing their causes. The contributions finance campaign expenditures, which in turn affect the parties' probabilities of winning the election. Magee et al. study the Nash equilibrium platforms that emerge when the parties act as Stackelberg leaders vis-à-vis the lobbies. $^{2}$

A second strand emanates from the writings of Stigler (1971) and Peltzman (1976) on domestic regulatory policy. Hillman (1982) ap-

as they use reduced-form political support functions to describe the objectives of each government (see the discussion below). Our analysis goes further in explicitly modeling the behavior of special-interest groups that determines a specific relationship between policy choices and political support. Also, they study a single sector, whereas we consider the structure of protection in noncooperative and cooperative equilibria with many goods.

${ }^{2}$ Findlay and Wellisz (1982) developed a reduced form of the Brock and Magee approach. In their formulation, a tariff formation function summarizes the relationship between the contributions (or other spending) of the two lobbies and the policies that emerge from the political process. They study Nash equilibrium contributions by the lobbies, taking the policy function as given. 
plied these ideas to trade policy formation, with further elaboration by Long and Vousden (1991). Their approach sees an incumbent government that is in a position to choose trade policy but is constrained by the prospect of the next election. The government recognizes that favors granted to special-interest groups may elicit financial and other support but also may cause dissatisfaction among elements of the general electorate. While avoiding the details of motives and actions, the authors summarize the relevant trade-off in a political support function: the government's "support" depends directly on its policies (because they affect voter well-being) and indirectly on policy through its effect on the rents accruing to certain interests. The government selects a policy to maximize its political support.

Our own approach, first developed in Grossman and Helpman (1994), combines elements of these two. As in the political support approach, we focus on an incumbent government that is in a position to set its nation's trade policies. We go beyond that approach, however, by modeling the actions available to the organized special interests and the incentives they face in deciding their political involvement. In other words, rather than specify a support function exogenously, we derive one from the equilibrium actions of profitmaximizing lobby groups. The lobbies in our formulation, like those in the electoral competition models of Magee et al., decide what size campaign contributions to offer the political representatives. But whereas Magee et al. see lobbies as setting their contributions after policy positions have been taken and with the sole objective of influencing the election outcome, we see the lobbies as offering contributions with the aim of influencing the policy announcements themselves. In other words, our lobbies seek to curry favor with politicians who covet their financial support. ${ }^{3}$

Our model is outlined as follows. Lobby groups represent factor owners with stakes in certain industries. Each lobby confronts its national government with a campaign contribution schedule, that is, a schedule relating its promised gift to the action taken by the government. ${ }^{4}$ These schedules will not, of course, be formal contracts, nor will they often be explicitly announced. Still, the government will

\footnotetext{
${ }^{3}$ In Grossman and Helpman (1994), we discuss the empirical evidence on campaign giving by political action committees in the United States. This evidence strongly suggests that "PAC money is interested money" with "more than electoral objective in mind" (Magelby and Nelson 1990, p. 55).

${ }^{4} \mathrm{An}$ issue arises as to whether the industry lobbies can also offer contributions to politicians in the other country's government. Interest groups do sometimes try to influence a foreign government's policy choices. But politicians often view gifts from foreign sources as tainted money. We choose to focus in the text on the case in which lobbies contribute only to their own national governments while treating the case with foreign contributions in a series of notes.
} 
know that an implicit relationship exists between the way it treats each organized lobby and the contributions it can expect to receive from that group. We assume that the contribution schedules are set to maximize the aggregate welfare of the lobby group's members, taking as given the schedules offered by the other organized groups.

Faced with the contribution schedules of the various lobbies, the incumbents choose a vector of trade taxes and subsidies on the various import and export goods. Their objective in this is to maximize their own political welfare. We allow the politicians' utility to depend on the welfare of the average voter and the total amount of political contributions. Average welfare is included in the government's objective to reflect the likelihood that prospects for reelection depend on the well-being of the general electorate. Contributions enter the government's utility function because campaign funds can be used for political advertising and because the contributions sometimes augment the candidates' personal fortunes or provide them with other political benefits (see Grossman and Helpman [1994] for more on this point).

In our earlier paper, we followed the political economy literature in assuming that the government could take world prices as given. Accordingly, there was no scope for interaction between the governments and no possibility for the interest groups in one country to influence policy outcomes elsewhere. Here, in contrast, we focus on the interactions between countries. First we characterize the Nash equilibrium of a noncooperative game between the two politically motivated governments. Then we consider a bargaining situation in which policies are set in an international negotiation.

\section{The Formal Model}

We consider the trade relations between two countries, "home" and "foreign." The countries have similar political and economic systems, although their tastes, endowments, and political conditions may differ. We describe in detail the political and economic structure of the home country.

Residents of the home country share identical additively separable preferences. Each individual maximizes a utility function of the form

$$
u=c_{Z}+\sum_{i=1}^{n} u_{i}\left(c_{X i}\right),
$$

where $c_{Z}$ is consumption of good $Z$ and $c_{X i}$ is consumption of good $X_{i}, i=1,2, \ldots, n$. The functions $u_{i}(\cdot)$ are differentiable, increasing, and strictly concave. Good $Z$ serves as a numeraire, with a world and domestic price equal to one. We denote by $p_{i}$ the domestic price of 
good $X_{i}$ in the home country, and $\pi_{i}$ represents its offshore price. ${ }^{5}$ With these preferences, each resident of the home country demands $d_{i}\left(p_{i}\right)$ units of $\operatorname{good} X_{i}, i=1,2, \ldots, n$, where $d_{i}(\cdot)$ is the inverse of $u_{i}^{\prime}(\cdot)$. The consumer devotes the remainder of his total spending of $E$ to the numeraire good, thereby attaining the utility level

$$
v(\mathbf{p}, E)=E+S(\mathbf{p}),
$$

where $\mathbf{p}=\left(p_{1}, p_{2}, \ldots, p_{n}\right)$ is the vector of home prices of the nonnumeraire goods and $S(\mathbf{p}) \equiv \Sigma_{i} u_{i}\left[d_{i}\left(p_{i}\right)\right]-\Sigma_{i} p_{i} d_{i}\left(p_{i}\right)$ is the consumer surplus enjoyed on these goods.

The numeraire good $Z$ can be produced from labor alone, with constant returns to scale. We assume that the aggregate labor supply, $l$, is sufficiently large to ensure a positive output of this good. Then we can choose units so that the competitive wage rate equals one. Each of the other goods is manufactured from labor and a sectorspecific input, also with constant returns to scale. The various specific inputs are available in inelastic supply. We denote by $\Pi_{i}\left(p_{i}\right)$ the aggregate rent accruing to the specific factor used in producing good $X_{i}$, and we note that the slope of this function gives the industry supply curve, that is,

$$
X_{i}\left(p_{i}\right)=\Pi_{i}^{\prime}\left(p_{i}\right)
$$

The government has a limited set of policy instruments at its disposal. We allow it to tax or subsidize trade in any of the nonnumeraire goods and to collect revenues or distribute tax receipts using a (neutral) head tax or subsidy. In other words, the government must use trade policies to effect any income redistribution between groups in the economy. In reality, governments appear to have difficulty in using direct and transparent instruments to transfer income, so they resort to less direct means instead. Our model highlights the role of trade policy as a potential tool of income redistribution.

The ad valorem trade taxes or subsidies drive a wedge between domestic and offshore prices. We represent these policies by the parameters $\tau_{i}$ such that $p_{i}=\tau_{i} \pi_{i}$. Then $\tau_{i}>1$ represents one plus the rate of tariff on an import good or one plus the rate of export subsidy on an export good. Similarly, $\tau_{i}<1$ represents an import subsidy or an export tax. The vector of trade policies $\tau=\left(\tau_{1}, \tau_{2}, \ldots, \tau_{n}\right)$ generates per capita government revenue of

$$
r(\boldsymbol{\tau}, \boldsymbol{\pi})=\Sigma_{i}\left(\tau_{i}-1\right) \pi_{i}\left[d_{i}\left(\tau_{i} \pi_{i}\right)-\frac{1}{N} X_{i}\left(\tau_{i} \pi_{i}\right)\right],
$$

\footnotetext{
${ }^{5}$ The offshore price need not be the same as the price prevailing in the foreign country, because the foreign country may impose trade taxes or subsidies of its own. We use $p_{i}^{*}$ to denote the internal price in the foreign country.
} 
where $\pi=\left(\pi_{1}, \pi_{2}, \ldots, \pi_{n}\right)$ and $N$ measures the total population, which we henceforth normalize to one. The government redistributes the tariff revenue evenly to the public.

Individuals collect income from several sources. Most earn wages as workers, and all receive the same transfer (possibly negative) from the government. In addition, some individuals own claims to one of the specific inputs. These assets are indivisible and nontradable (as, e.g., with claims to sector-specific human capital), so individuals cannot hold more than one type. Clearly, those who own some of the specific factor used in industry $i$ will see their income tied to the domestic price of good $X_{i}$. These individuals have a direct stake in the trade policy $\tau_{i}$, in addition to their general interest as consumers in all policies that affect domestic prices.

The owners of the specific input used in sector $i$, with their common desire for protection (or export subsidies) for their industry, may choose to join forces to express their policy wishes to the incumbent government. We assume that the various owners of some (or perhaps all) of the specific inputs form political action groups, but the owners of the remaining specific inputs (if any) fail to organize politically. The set of organized industries is taken as exogenous here. The organized groups enjoy a political advantage relative to individual factor owners inasmuch as the groups control substantially greater resources than most individuals. With these vast resources at their disposal, the lobbyists can gain access to politicians to communicate their political demands. We assume that the lobbies express their demands in the form of contribution schedules; that is, they offer to contribute to the campaign funds of the incumbent politicians an amount that depends on the particular policies implemented by the government, as well as perhaps the concessions that the politicians manage to extract from the foreign government in the course of any trade negotiation. While the unorganized individuals (including those individuals who own none of the specific inputs) might also wish to "bid" for trade policies in this way, we assume that the politicians will not take the time to hear their offers, which are likely to be small in view of the limited income of an individual factor owner and the limited stake that any one person has in the policy outcome. In short, we assume that politically unorganized individuals have no means to influence policy with their campaign contributions; they enter the political process only as voters.

The organized input owners coordinate their political activities so as to maximize their joint welfare. The lobby representing industry $i$ submits the contribution schedule $C_{i}(\tau, \cdot)$ that maximizes

$$
v^{i}=\tilde{W}_{i}(\boldsymbol{\tau}, \boldsymbol{\pi})-C_{i}(\boldsymbol{\tau}, \cdot),
$$


where

$$
\tilde{W}_{i}(\boldsymbol{\tau}, \boldsymbol{\pi}) \equiv l_{i}+\Pi_{i}\left(\tau_{i} \pi_{i}\right)+\alpha_{i}[r(\boldsymbol{\tau}, \boldsymbol{\pi})+S(\boldsymbol{\tau} \pi)],
$$

$\alpha_{i}$ is the fraction of the population that owns the specific input used in sector $i$ (also their measure, given that $N=1$ ), and $l_{i}$ is the joint labor endowment of these factor owners. ${ }^{6}$ Equation (6) gives the total gross-of-contributions welfare of the $\alpha_{i}$ members of lobby group $i$, which they derive from wages, quasi rents, transfers from the government, and surplus from consuming the nonnumeraire goods (see eq. [2]). Notice that we have omitted all but one argument of the contribution schedule. This allows us to distinguish the case of a trade war, where the contribution schedule depends only on the actions of the home government, from that of trade talks, where the contributions may also depend on actions taken by the foreign government under any agreement.

Facing the contribution schedules offered by the various lobbies, the incumbents set trade policy-either unilaterally or through a process of international bargaining - so as to maximize their political welfare. We assume that the politicians care about the accumulation of campaign contributions and perhaps also about the welfare of the average voter. As we discussed in Section II, the politicians may value contributions as a source of funding for campaign advertisements and possibly for other reasons. A concern for average welfare will arise if the prospects for reelection depend on the average voter's prosperity. We posit a linear form for the government's objective function, namely

$$
G=\Sigma_{i \in L} C_{i}(\tau, \cdot)+a \tilde{W}(\tau, \pi), \quad a \geq 0,
$$

where $L$ is the set of organized industries and

$$
\tilde{W}(\boldsymbol{\tau}, \boldsymbol{\pi}) \equiv l+\Sigma_{i} \Pi_{i}\left(\tau_{i} \pi_{i}\right)+r(\boldsymbol{\tau}, \boldsymbol{\pi})+S(\boldsymbol{\tau} \pi)
$$

measures average (gross) welfare. The parameter $a$ in (7) represents the government's weighting of a dollar of social welfare compared to a dollar of campaign contributions, considering both the perceived political value of the funding and the indirect cost associated with the contributor's loss of welfare.

As we mentioned before, the foreign country has a similar political and economic structure, although the subutility functions $u_{i}^{*}(\cdot)$, the profit functions $\Pi_{i}^{*}(\cdot)$, the set of organized industries $L^{*}$, the number $\alpha_{i}^{*}$ of voters with claims to the specific input used in sector $i$, and the weight $a^{*}$ that the government places on aggregate welfare relative to contributions may differ from those in the home country (the

\footnotetext{
${ }^{6}$ In (6) we have used the notation $\tau \pi$ in the argument of $S(\cdot)$ to represent the vector $\left(\tau_{1} \pi_{1}, \tau_{2} \pi_{2}, \ldots, \tau_{n} \pi_{n}\right)$. Thus $\tau \pi=\mathbf{P}$ is the vector of home country prices.
} 
analogous functions and parameters have no asterisks). Equations analogous to (1)-(8) apply to the foreign country, where trade policies are $\tau^{*}=\left(\tau_{1}^{*}, \tau_{2}^{*}, \ldots, \tau_{n}^{*}\right)$, internal prices are $\mathbf{p}^{*}=\left(p_{1}^{*}, p_{2}^{*}, \ldots\right.$, $\left.p_{n}^{*}\right)$, output in sector $i$ is $X_{i}^{*}$, and so forth.

Having specified the production and demand sides of each economy, we turn now to the international equilibrium. Net imports of good $i$ in the home country are $M_{i}\left(p_{i}\right)=d_{i}\left(p_{i}\right)-X_{i}\left(p_{i}\right)$, and those in the foreign country equal $M_{i}^{*}\left(p_{i}^{*}\right)=d_{i}^{*}\left(p_{i}^{*}\right)-X_{i}^{*}\left(p_{i}^{*}\right)$. Recall that $p_{i}=\tau_{i} \pi_{i}$ and $p_{i}^{*}=\tau_{i}^{*} \pi_{i}$. Then world product markets clear when

$$
M_{i}\left(\tau_{i} \pi_{i}\right)+M_{i}^{*}\left(\tau_{i}^{*} \pi_{i}\right)=0, \quad i=1,2, \ldots, n .
$$

This equation allows us to solve for the market-clearing price of good $X_{i}$ as a function of the industry trade taxes or subsidies imposed by the two countries. We denote this functional relationship by $\pi_{i}\left(\tau_{i}\right.$, $\left.\tau_{i}^{*}\right)$. It follows from (9) that the functions $\pi_{i}(\cdot)$ are homogeneous of degree minus one; that is, if the home country were to increase its tariff on imports of some good and the foreign country increased its export subsidy by the same percentage amount, then the world price would fall so as to leave the domestic prices in each country unchanged.

Using (9), we can express the (gross-of-contributions) welfare levels of the organized interest groups and of the average voter in each country as functions of the trade policy vectors $\tau$ and $\tau^{*}$. For example, the expression in (6) for the gross welfare of owners of the specific factor used in home industry $i$ becomes $W_{i}\left(\tau, \tau^{*}\right) \equiv \tilde{W}_{i}\left[\boldsymbol{\tau}, \boldsymbol{\pi}\left(\boldsymbol{\tau}, \boldsymbol{\tau}^{*}\right)\right]$, and the average welfare of home voters can be written as $W\left(\tau, \tau^{*}\right) \equiv$ $\tilde{W}\left[\boldsymbol{\tau}, \boldsymbol{\pi}\left(\boldsymbol{\tau}, \boldsymbol{\tau}^{*}\right)\right]$. Inserting these functions into (5) and (7) and their foreign analogues gives the objectives of the lobbies and politicians as functions of the trade policy vectors in each country.

We describe finally the sequence of actions by the various agents in our two-country model. The lobbies in each country move first, setting contribution schedules that link their gifts to the various possible policy outcomes. The lobbies act simultaneously and noncooperatively, each taking as given the schedules of all other lobbies in the same and the other country. Then the governments set their national trade policies. In Section IV, where we study trade wars, these policies are set in a noncooperative, simultaneous-move game. In Section V, which deals with international negotiations, the policies emerge from the specified bargaining process. In both cases, we assume that the implicit contracts between the politicians and interest groups in one country (i.e., the contribution schedules that have been communicated by the lobbyists to the government) are not observable to the government in the other. The importance of this assumption will become clear as we go along. 


\section{Trade Wars}

We begin our analysis of the international economic relations between politically motivated governments with the case of a trade war. Here, the governments behave unilaterally, ignoring the impacts of their actions on political and economic agents in the opposite country. While purely noncooperative outcomes are unlikely to emerge in a world with repeated interactions and many forums for trade discussions, the extreme case of noncooperation sheds light on the political forces that shape trade policies during the frequent departures from harmony and cooperation in the trading realm.

Let us define an equilibrium response by each country to an arbitrary policy choice of the other. We use the home country to illustrate, although a similar definition applies to the foreign country.

Definition 1. Let $\tau^{*}$ be an arbitrary trade policy vector of the foreign country. Then a set of feasible contribution functions $\left\{C_{i}^{o}\right\}_{i \in L}$ and a trade policy vector $\tau^{o}$ are an equilibrium response to $\tau^{*}$ if $(a)$

$$
\boldsymbol{\tau}^{o}=\underset{\tau}{\arg \max } \Sigma_{i \in L} C_{i}^{o}\left(\boldsymbol{\tau} ; \boldsymbol{\tau}^{*}\right)+a W\left(\boldsymbol{\tau}, \boldsymbol{\tau}^{*}\right)
$$

and $(b)$ for every organized interest group $i \in L$ there does not exist a feasible contribution function $C_{i}\left(\boldsymbol{\tau} ; \boldsymbol{\tau}^{*}\right)$ and a trade policy vector $\boldsymbol{\tau}^{i}$ such that (i)

$$
\boldsymbol{\tau}^{i}=\underset{\boldsymbol{\tau}}{\arg \max } C_{i}\left(\boldsymbol{\tau} ; \boldsymbol{\tau}^{*}\right)+\Sigma_{j \neq i, j \in L} C_{j}^{o}\left(\boldsymbol{\tau} ; \boldsymbol{\tau}^{*}\right)+a W\left(\boldsymbol{\tau}, \boldsymbol{\tau}^{*}\right)
$$

and (ii)

$$
W_{i}\left(\boldsymbol{\tau}^{i}, \boldsymbol{\tau}^{*}\right)-C_{i}\left(\boldsymbol{\tau}^{i} ; \boldsymbol{\tau}^{*}\right)>W_{i}\left(\boldsymbol{\tau}^{o}, \boldsymbol{\tau}^{*}\right)-C_{i}^{o}\left(\boldsymbol{\tau}^{o} ; \boldsymbol{\tau}^{*}\right) .
$$

An equilibrium response comprises a set of feasible contribution schedules and a policy vector. Each contribution schedule prescribes a political donation for each trade policy vector $\tau$ that the home government might select. Feasible schedules are those that promise only nonnegative offers that do not exceed the aggregate income of the group's members. Condition $a$ of the definition stipulates that the politicians select the policy vector that best serves their own interest, given the policy of the foreign government and the contribution schedules offered by the domestic lobbies. Condition $b$ states that, given the set of contributions offered by all lobbies other than itself, no individual lobby $i$ can improve its lot by setting a contribution schedule $C_{i}(\cdot)$ different from $C_{i}^{o}(\cdot)$, thereby inducing the home government to choose the policy vector $\tau^{i}$.

Several aspects of this definition bear further discussion. First, our definition supposes that the lobbies do not cooperate with one an- 
other. While it is occasionally the case that several lobbies in a country will coordinate their activities to pursue a common goal and even that lobbies in different countries will join forces, the norm is certainly for the various industry representatives to take independent political action. One explanation for this observation might be that pressure groups cannot write binding contracts specifying their contributions to politicians and other political activities. In the absence of such contracts, it would be difficult for the different lobby groups to enforce any cooperative agreement among themselves. Also, in our model, the scope for cooperation between lobbies in any one country is limited because the interests of different producers are mostly opposed to one another. Lobbies representing the same industry in different countries also have opposing views about desirable policy interventions, as we shall see.

Our definition also presumes that the lobbies condition their promised contributions on the expected policy choices of the other country's government. In other words, the lobbies take the other country's policy as given, even though these lobbies make their decisions before the governments make theirs. The lobbies certainly would wish to influence the choices of the other government if it were possible to do so. But here is where our assumption that a lobby's offers to its own government cannot be observed by the other government comes into play. If the home lobbies could make their promises observable to foreign politicians and if they could commit to their contribution schedules immutably, then the lobbies would set their schedules strategically in order to induce a favorable policy response by the foreign government. The situation would be similar to that analyzed by Fershtman and Judd (1987), who showed that the owners of a firm generally will want to set a compensation schedule that gives the firm's managers an incentive to act aggressively in oligopolistic competition against other firms. But, as Katz (1991) later argued, a strategic design of an agent's compensation schedule can bear fruit in a delegation game (i.e., a game in which agents play on behalf of principals) only if the contracts between principal and agent are observable to the opposing players. Otherwise, the opposing players will not be influenced by (unobserved) manipulation of the principal-agent contract, and so there can be no gain to the principals (in our case, the home lobbies) from such manipulation.

It is natural for us to assume that contribution schedules cannot be observed abroad, for at least two reasons. First, it might be problematic for special-interest groups to be open and explicit about their willingness to pay the government for favorable treatment. Second, even if the interest groups were to announce their intention to vary their support according to the positions taken by the politicians, these 
promises would not be legally binding and policy makers abroad would not know whether there were further details or subsequent agreements besides those that had been made public. In cases in which multiple agreements or renegotiation is possible, a lobby's announcement of its contribution schedule carries little commitment value (see Katz 1991). Accordingly, we feel justified in studying an equilibrium in which the industry groups condition their lobbying strategies on what they expect will be the other government's policy choice, but do not see themselves as able to influence those policies by their own choice of contribution schedule.

To find the equilibrium responses for each country, we proceed as in Grossman and Helpman (1994). There we characterized equilibrium trade policies for a small country that takes external prices as given. We noted the applicability of the theory of common agency developed by Bernheim and Whinston (1986), wherein a single actor acts simultaneously as the agent for several different principals. In the present context, once we take the foreign policy vector as given, we have a situation in which the home government acts as an agent for the various special-interest groups in the home country. We have already derived the payoffs to the principals and the agent for every action open to the latter, so we can proceed to apply the BernheimWhinston results to characterize the equilibrium responses.

We know from lemma 2 in Bernheim and Whinston (1986) (or proposition 1 in Grossman and Helpman [1994]) that the equilibrium policy response to $\tau^{*}$ satisfies, in addition to condition $a$ of definition 1 , the following requirement that is implied by condition $b:^{7}$

$$
\begin{aligned}
\boldsymbol{\tau}^{o}= & \underset{\boldsymbol{\tau}}{\arg \max } W_{i}\left(\boldsymbol{\tau}, \boldsymbol{\tau}^{*}\right)-C_{i}^{o}\left(\boldsymbol{\tau} ; \boldsymbol{\tau}^{*}\right) \\
& +\Sigma_{j \in L} C_{j}^{o}\left(\boldsymbol{\tau} ; \boldsymbol{\tau}^{*}\right)+a W\left(\boldsymbol{\tau}, \boldsymbol{\tau}^{*}\right) \quad \text { for every } i \in L .
\end{aligned}
$$

This condition has a simple interpretation: the equilibrium trade policy vector must maximize the joint welfare of each lobby $i$ and the government, when the contribution schedules of all lobbies other than $i$ are taken as given. If this were not the case, lobby $i$ could reformulate its schedule to induce the government to choose the jointly optimal policy vector instead of the alternative, and it could do so in such a way as to share in the surplus from the switch in policy. In equilibrium there can exist no such possibilities for a lobby to improve its lot. Of course, the same holds true for the foreign lobbies, so that an equation analogous to (10) applies to $\tau^{* 0}$.

Let us assume now that the lobbies set contribution schedules that

7 This is a necessary condition for an equilibrium. All the necessary and sufficient conditions are given in proposition 1 of Grossman and Helpman (1994). 
are differentiable, at least around the equilibrium point. ${ }^{8}$ We have argued in Grossman and Helpman (1994) that there are compelling reasons for focusing on contribution schedules that have this property. For example, differentiable schedules may be robust to small calculation errors. With differentiability, a trade policy vector that satisfies (10) also satisfies the first-order condition

$$
\begin{gathered}
\nabla_{\tau} W_{i}\left(\boldsymbol{\tau}^{o} ; \boldsymbol{\tau}^{*}\right)-\nabla_{\tau} C_{i}^{o}\left(\boldsymbol{\tau}^{o}, \boldsymbol{\tau}^{*}\right)+\sum_{j \in L} \nabla_{\boldsymbol{\tau}} C_{j}^{o}\left(\boldsymbol{\tau}^{o} ; \boldsymbol{\tau}^{*}\right) \\
+a \nabla_{\boldsymbol{\tau}} W\left(\boldsymbol{\tau}^{o}, \boldsymbol{\tau}^{*}\right)=0 \text { for all } i \in L .
\end{gathered}
$$

The home politicians' utility maximization ensures, by part $a$ of definition 1 , that

$$
\Sigma_{j \in L} \nabla_{\tau} C_{j}^{o}\left(\boldsymbol{\tau}^{o} ; \boldsymbol{\tau}^{*}\right)+a \nabla_{\tau} W\left(\boldsymbol{\tau}^{o}, \boldsymbol{\tau}^{*}\right)=0 .
$$

Taken together, (11) and (12) imply

$$
\nabla_{\tau} C_{i}^{o}\left(\tau^{o} ; \tau^{*}\right)=\nabla_{\tau} W_{i}\left(\tau^{o}, \tau^{*}\right) \quad \text { for all } i \in L ;
$$

that is, the contribution schedules are set so that the marginal change in the donation for a small change in home policy (with the foreign policy taken as given) matches the effect of the policy change on the lobby's gross welfare. In Grossman and Helpman (1994), we referred to this property of the equilibrium contribution schedules as local truthfulness.

We sum equation (13) over all $i$ and substitute the result into (12) to derive

$$
\sum_{i \in L} \nabla_{\tau} W_{i}\left(\boldsymbol{\tau}^{o}, \boldsymbol{\tau}^{*}\right)+a \nabla_{\tau} W\left(\boldsymbol{\tau}^{o}, \boldsymbol{\tau}^{*}\right)=0 .
$$

This equation allows us to compute the equilibrium home policy response to an arbitrary foreign policy vector $\tau^{*}$. Similarly, we have

$$
\Sigma_{i \in L^{*}} \nabla_{\tau^{*}} W_{i}^{*}\left(\tau^{* o}, \boldsymbol{\tau}\right)+a^{*} \nabla_{\tau^{*}} W^{*}\left(\boldsymbol{\tau}^{* o}, \boldsymbol{\tau}\right)=0,
$$

which gives the foreign equilibrium response to an arbitrary home policy vector.

At last we are ready to define a full equilibrium in the trade war. When the policies are set, each government makes an equilibrium response to what it expects the other's policy will be. We can invoke the concept of a Nash equilibrium as follows.

Definition 2. A noncooperative trade policy equilibrium consists of sets of political contribution functions $\left\{C_{i}^{o}\right\}_{i \in L}$ and $\left\{C_{i}^{* o}\right\}_{i \in L^{*}}$ and a

${ }^{8}$ Typically, the contribution schedules would not be differentiable where the constraint that payments must be nonnegative becomes binding, i.e., where $C_{i}(\cdot)=0$. However, this is not a problem for our arguments since we shall assume differentiability only around equilibria in which $C_{i}^{o}\left(\tau^{0} ; \tau^{* 0}\right)>0$ for all $i$. 
pair of trade policy vectors $\tau^{o}$ and $\tau^{* o}$ such that $\left[\left\{C_{i}^{o}\right\}_{i \in L}, \tau^{o}\right]$ is an equilibrium response to $\tau^{* o}$ and $\left[\left\{C_{i}^{*}\right\}_{i \in L^{*}}, \tau^{* 0}\right]$ is an equilibrium response to $\tau^{\circ}$.

We proceed now to characterize the equilibrium policy vectors by substituting $\tau^{* o}$ for $\tau^{*}$ in (14) and $\tau^{o}$ for $\tau$ in $\left(14^{*}\right)$ and then treating these equations as a system of simultaneous equations. We calculate the derivatives in (14) using (4), (6), (8), and the definitions of the import functions $M_{i}(\cdot)$ and the gross benefit functions $W_{i}(\cdot)$ and $W(\cdot)$. This gives

$$
\begin{gathered}
\left(I_{i L}-\alpha_{L}\right)\left(\pi_{i}+\tau_{i}^{o} \pi_{i 1}\right) X_{i}+\left(a+\alpha_{L}\right) \\
\times\left[\left(\tau_{i}-1\right) \pi_{i}\left(\pi_{i}+\tau_{i}^{o} \pi_{i 1}\right) M_{i}^{\prime}-\pi_{i 1} M_{i}\right]=0,
\end{gathered}
$$

where $I_{i L}$ is an indicator variable that equals one if industry $i$ is politically organized and zero otherwise, and $\alpha_{L} \equiv \Sigma_{j \in L} \alpha_{j}$ is the fraction of voters that are represented by a lobby. From (9) we find the partials of the world price functions, $\pi_{j}(\cdot) .{ }^{9}$ Substituting them into (15) yields an expression for the home country's equilibrium policy, namely

$$
\tau_{i}^{o}-1=-\frac{I_{i L}-\alpha_{L}}{a+\alpha_{L}} \frac{X_{i}}{\pi_{i} M_{i}^{\prime}}+\frac{1}{e_{i}^{*}} \text { for } i=1,2, \ldots, n,
$$

where $e_{i}^{*} \equiv \tau_{i}^{*} \pi_{i} M_{i}^{* \prime} / M_{i}^{*}$ is the elasticity of foreign import demand or export supply (depending on whether $M_{i}^{*}$ is positive or negative). An analogous equation describes the equilibrium foreign trade policy; that is,

$$
\tau_{i}^{* o}-1=-\frac{I_{i L}^{*}-\alpha_{L}^{*}}{a^{*}+\alpha_{L}^{*}} \frac{X_{i}^{*}}{\pi_{i} M_{i}^{* \prime}}+\frac{1}{e_{i}} \text { for } i=1,2, \ldots, n,
$$

where $e_{i} \equiv \tau_{i} \pi_{i} M_{i}^{\prime} / M_{i}$ is the home country's import demand or export supply elasticity.

Equations (16) and $\left(16^{*}\right)$ express the ad valorem trade tax and subsidy rates in each country as sums of two components. These components represent, respectively, the political support and terms-oftrade motives for trade intervention. The first component has exactly the same form as the expression in Grossman and Helpman (1994) for the equilibrium policy in a small country facing fixed world prices. It reflects a balancing of the deadweight loss associated with trade policies (given the terms of trade) and the income gains that specialinterest groups can capture via such policies. The second component represents the familiar "optimum tariff" (or export tax) that applies in a large country with a benevolent dictator. Given the balancing of

${ }^{9}$ We have $\pi_{i 1} / \pi_{i}=-M_{i}^{\prime} /\left(\tau_{i} M_{i}^{\prime}+\tau_{i}^{*} M_{i}^{* \prime}\right)$ and $\pi_{i 2} / \pi_{i}=-M_{i}^{* \prime} /\left(\tau_{i} M_{i}^{\prime}+\tau_{i}^{*} M_{i}^{* \prime}\right)$. 
special and general interests implicit in the first term, this second term enters the political calculus as an added reason why noncooperating governments will wish to tax international trade.

It is apparent from (16) and $\left(16^{*}\right)$ that an organized importcompeting industry emerges from a trade war with a protective tariff (since $e_{i}^{*}>0$ when the foreign country exports good $i$ ), whereas an unorganized home export industry suffers an export tax (since $e_{i}^{*}<$ 0 when the foreign country imports good $i$ ). In the former case, the terms-of-trade considerations reinforce the industry's lobbying efforts. In the latter case, the government's desire to drive up the world price with an export tax finds support from all organized groups, whose members are consumers of the exportable good. Only in cases of organized export sectors and unorganized import sectors do the special and general interests come into conflict-at least as far as the sign, as opposed to the size, of the desired trade policy is concerned.

Consider, for example, an organized export industry (so that $e_{i}^{*}<$ 0 and $I_{i L}=1$ ). The industry's prospects for securing an export subsidy are better the greater industry output, the smaller the price sensitivities of domestic supply and demand, and the smaller the weight $a$ that home politicians place on average welfare. A large domestic output raises the stakes for owners of the specific input and makes them willing to bid more for support. Such bids have a greater influence on the politicians when they are less concerned with the public interest and when the deadweight loss associated with a given departure from free trade is small (i.e., $\left|M_{i}^{\prime}\right|$ is small). On the other hand, for a given value of $a$ and given conditions in the domestic market, the more inelastic the foreign import demand curve, the more inclined the home government will be to choose an export tax as its equilibrium policy. This accords with intuition since the home country's market power in trade varies with the inverse of the foreign elasticity, so the potential social gains from trade taxes become larger as $\left|e_{i}^{*}\right|$ declines. We note that the second term can outweigh the first even if the government pays no attention whatsoever to national welfare (i.e., $a=0$ ). The reason is that the members of the various interest groups themselves share in the terms-of-trade gains from trade taxes, and they may collectively bid for an export tax for industry $i$ even though the lobby that represents the industry presses for a subsidy. ${ }^{10}$

\footnotetext{
${ }^{10}$ In the case in which lobbies can contribute to foreign politicians as well as to their own national government, the lobbies still find it optimal to be locally truthful in their contribution offers to each government. The implication is that the left-hand side of (15) has some additional terms representing the effect of a marginal change in the home tariff on the aggregate welfare of foreign interest group members. To calculate the
} 
It is interesting to compare the policy outcomes in our model with those derived by Johnson (1954) under the assumption that governments maximize social welfare. This comparison allows us to isolate the role that domestic politics play in determining the outcome of a trade war. We note that our model reproduces the Johnson equilibrium as a limiting case when the governments care overwhelmingly about voters' welfare (so that $a$ and $a^{*}$ approach infinity). ${ }^{11}$ Then the governments apply the familiar inverse elasticity rules in setting trade taxes.

In making the comparison, we focus on a special case in which both countries have constant trade elasticities. We may limit our attention to the outcome in a single industry because the equilibrium policy responses depend only on the characteristics of industry $i$ and aggregate variables (see [16] and $\left[16^{*}\right]$ ). For concreteness, we make the home country the importer of good $X_{i}$. Then its import demand curve is given by $M=m(\tau \pi)^{-\epsilon}$, with $m>0$ and $\epsilon=-e_{i}>1 .{ }^{12}$ The foreign country's export supply function has the form $-M^{*}=$ $m^{*}\left(\tau^{*} \pi\right)^{\epsilon^{*}}$, with $m^{*}>0$ and $\epsilon^{*}=e_{i}^{*}>0$.

Figure 1 shows the Johnson equilibrium at point $J$. This point lies at the intersection of two best-response functions, $B B$ for the home country and $B^{*} B^{*}$ for the foreign country, where $B$ refers to the

domestic tariff response functions, we would need to add to the left-hand side of (15) the following expression:

$$
\left(I_{i L}^{*}-\alpha_{L}^{*}\right) \tau_{i}^{*} \pi_{i 1} X_{i}^{*}+\alpha_{L}^{*}\left[\left(\tau_{i}^{*}-1\right) \pi_{i} \tau_{i}^{*} M_{i}^{* \prime}-M_{i}^{*}\right] \pi_{i 1} .
$$

The resulting analogue to the tariff formula (16) is somewhat complicated but is easily interpreted for the case in which the lobby groups are a negligible fraction of the voting population in each country; i.e., $\alpha_{L}=\alpha_{L}^{*}=0$. In this special case, the home country's equilibrium tariff is given by

$$
\tau_{i}^{o}-1=-\frac{I_{i L}}{a} \frac{X_{i}}{\pi_{i} M_{i}^{\prime}}+\frac{I_{i L}^{*}}{a} \frac{X_{i}^{*}}{\pi_{i} M_{i}^{* \prime}}+\frac{1}{e^{*}}
$$

when there are contributions by both national and foreign lobbies. Comparing (16) and $\left(16^{\prime}\right)$, we see that influence-seeking by foreign lobbies serves to reduce the size of the home tariff response to any given foreign tariff, the more so the greater the foreign industry's output and the less price responsive the foreign country's export supply. The foreign output $X_{i}^{*}$ measures the size and hence political clout of the foreign industry, and the slope of the foreign export supply measures the home government's willingness to accede to its wishes for a smaller tariff, in view of the induced effect on the international price.

${ }^{11}$ The Johnson equilibrium also obtains when all voters belong to a lobby group and all industries are politically organized. In this case, all individuals are able to express their political demands to the politicians, and so all are equally represented in the political process. The opposing interest groups neutralize one another in their attempts to transfer income to themselves, and what remains is only the terms-of-trade motive for trade policy that potentially benefits them all. Becker (1983) derives a similar neutrality result in a somewhat different model of the political process.

${ }^{12}$ We omit the industry subscript for the time being since all parameters and variables refer to industry $i$. 


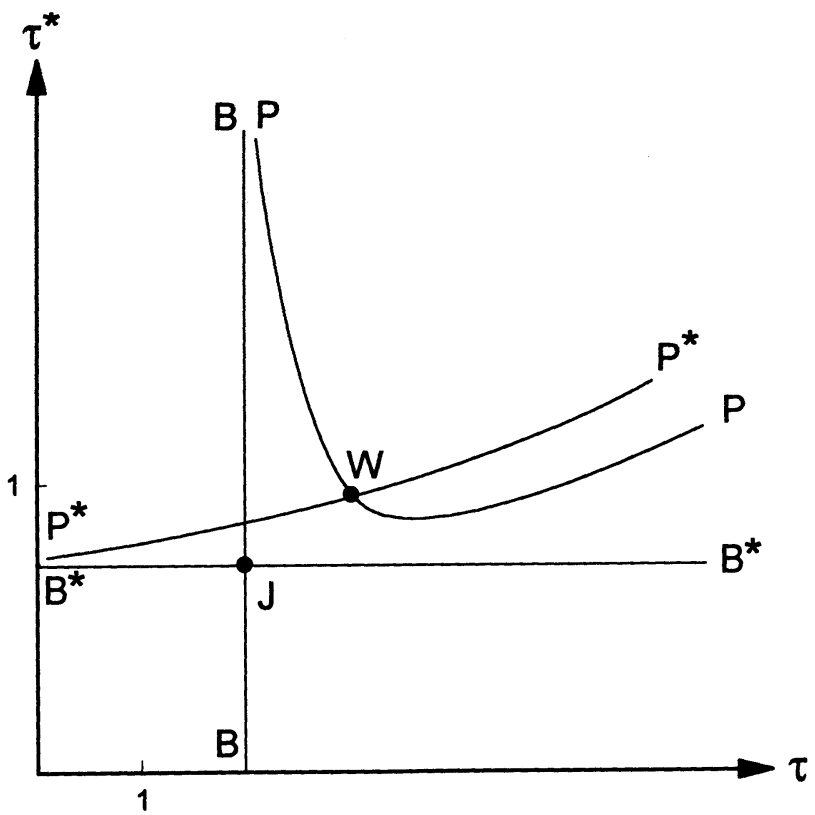

Fig. 1.-Trade war equilibrium

benevolent dictators that rule each country. The curves are vertical and horizontal, respectively, in the constant elasticity case. The inverse elasticity rule gives the equilibrium policies in the Johnson equilibrium, $\tau_{J}=1+\left(1 / \epsilon^{*}\right)$ and $\tau_{J}^{*}=1-(1 / \epsilon)$. These are, of course, a tariff at home $\left(\tau_{J}>1\right)$ and an export tax abroad $\left(\tau_{J}^{*}<1\right)$.

In the trade war between politically motivated governments, the market-clearing world price for good $i$ can be found using (9) and the expressions that define the constant elasticity import demand and export supply functions. We find

$$
\pi\left(\tau, \tau^{*}\right)=\left(\frac{m}{m^{*}}\right)^{1 /\left(\epsilon+\epsilon^{*}\right)}\left(\frac{1}{\tau}\right)^{\epsilon /\left(\epsilon+\epsilon^{*}\right)}\left(\frac{1}{\tau^{*}}\right)^{\epsilon^{* /\left(\epsilon+\epsilon^{*}\right)} .}
$$

Also, (16) and (16*) give the equilibrium policy responses, which in the constant elasticity case can be written as

$$
\tau=\left(1+\frac{1}{\epsilon^{*}}\right)\left[1-\frac{I_{L}-\alpha_{L}}{a+\alpha_{L}} \frac{X(\tau \pi)}{\epsilon m(\tau \pi)^{-\epsilon}}\right]^{-1}
$$

and

$$
\tau^{*}=\left(1-\frac{1}{\epsilon}\right)\left[1-\frac{I_{L}^{*}-\alpha_{L}^{*}}{a^{*}+\alpha_{L}^{*}} \frac{X^{*}\left(\tau^{*} \pi\right)}{\epsilon^{*} m^{*}\left(\tau^{*} \pi\right)^{\epsilon^{*}}}\right]^{-1},
$$


where the $\pi$ in $(18)$ and $\left(18^{*}\right)$ represents the equilibrium $\pi\left(\tau, \tau^{*}\right)$ given in (17).

Figure 1 shows the equilibrium responses for an industry with active lobby groups in both countries (i.e., $I_{L}=I_{L}^{*}=1$ ). The home country's equilibrium response function $(18)$ is represented by $P P$ $\left(P\right.$ for political) and the foreign country's $\left(18^{*}\right)$ by $P^{*} P^{*}$. The $P P$ curve lies everywhere to the right of $B B$ and has a $U$-shape: it asymptotes to $B B$ at $\tau=1+\left(1 / \epsilon^{*}\right)$ and to a ray from the origin as $\tau$ grows large. ${ }^{13}$ The $P^{*} P^{*}$ curve lies everywhere above $B^{*} B^{*}$ and always slopes upward. ${ }^{14}$

Point $W$ depicts the political equilibrium in the trade war. ${ }^{15}$ This point lies to the northeast of the Johnson equilibrium at point $J$. Evidently, the politically motivated governments tilt trade policies in favor of their organized special interests; the home tariff is higher in the political equilibrium than in the Johnson equilibrium, whereas the foreign export tax is lower or possibly even a subsidy. ${ }^{16}$

Next we examine how the policy outcome changes when the political climate does. Suppose that the home politicians were to become less sensitive to the public interest and more concerned with their campaign finances; that is, consider a decrease in $a$. For the case of a home import good with active lobbies in each country, figure 1 describes the initial equilibrium. A decline in $a$ causes the $P P$ curve to shift up, moving the equilibrium up and to the right along the fixed $P^{*} P^{*}$ schedule. ${ }^{17}$ The new equilibrium entails a higher home

${ }^{13}$ From (18) we see that $\tau \rightarrow \infty$ if and only if the term in brackets on the right-hand side approaches zero. Since $X(\tau \pi) /(\tau \pi)^{-\epsilon}$ is an increasing function of $\tau \pi$, this gives a unique value for $\tau \pi$ and therefore $\tau / \tau^{*}$ (see [17]) as $\tau$ grows large.

${ }^{14}$ The right-hand side of $\left(18^{*}\right)$ declines in the foreign price $p^{*}=\tau^{*} \pi$ because foreign exports $\left(m^{*} p^{\left.* \epsilon^{*}\right)}\right.$, which are the difference between foreign output and demand, are more sensitive to $p^{*}$ than foreign supply $\left(X^{*}\right)$. But, from (17), we see that the foreign price $\tau^{*} \pi$ increases in $\tau^{*} / \tau$. It follows that $P^{*} P^{*}$ must slope upward. We note that the slope would be ambiguous if the sector's input owners were unorganized (i.e., if $I_{L}^{*}=0$ ).

${ }^{15}$ The diagram shows a unique equilibrium, which exists when the $P^{*} P^{*}$ curve is steeper than the $P P$ curve for $\tau$ and $\tau^{*}$ large. If the $P P$ curve becomes steeper as $\tau$ and $\tau^{*}$ grow large, then the curves have either zero or two intersections. In the event that there are two, our remarks apply only to the equilibrium associated with the first crossing.

${ }^{16}$ The trade war generates both higher import tariffs and higher export taxes than the Johnson equilibrium for industries in which the import-competing interests are organized but the export interests are not. Where the export interests are organized and the import-competing interests are not, the trade taxes are lower in both countries than at $J$ and may even turn to subsidies in one or both countries. Finally, import tariffs are lower and export taxes higher than at $J$ in industries that have organized lobbies in neither country; then the organized groups representing other industries bid unopposed for lower consumer prices, at the expense of the unrepresented specific factor owners.

${ }^{17}$ Given $\tau$, eq. (18) requires an increase in $\tau^{*}$ in response to a decline in $a$, so that $\pi$ rises and $X / M$ falls. 
tariff and a lower foreign export tax (or higher export subsidy). The increase in the tariff comes about in the first instance because the lobby perceives a smaller marginal cost of "buying" protection from the government. Since the foreign lobbies and the foreign government expect a more protectionist stance from the home government, the political calculus changes there as well. In particular, a higher domestic tariff means, ceteris paribus, a lower world price for the good. This decreases both the private benefit and social cost of an export subsidy, but the latter falls by proportionately more. Thus the industry's willingness to pay for a subsidy (or to resist a tax) declines by less than the cost to the government of providing the favor. The new foreign policy is more favorable to the foreign industry.

We note that the rise in the import tariff and the fall in the export tax have offsetting implications for internal prices in each country. The increase in the home tariff raises the home price despite the resultant improvement in the terms of trade, but the fall in the foreign export tax pushes the home price down via its effect on $\pi$. Similarly, the increase in $\tau^{*}$ puts upward pressure on $p^{*}$, but the terms-oftrade movement associated with the rise in $\tau$ works in the opposite direction. The figure shows, however, that $\tau / \tau^{*}$ must rise. ${ }^{18}$ Since $\tau \pi$ is an increasing function of $\tau / \tau^{*}$ and $\tau^{*} \pi$ is a decreasing function of this same ratio, the decline in $a$ causes the internal price of a home import good to rise at home and to fall abroad.

The change in the political environment affects organized export industries in much the same way. Figure 2 shows the policy outcome for such a sector. Since our labeling convention makes the foreign country the exporter of the good in question, we represent a reduction in the government's concern about aggregate welfare by a cut in $a^{*}$. This shifts the $P^{*} P^{*}$ curve to the left. The export tax (or subsidy) may rise or fall, whereas the import tariff always falls. But no matter which way the exporting country's policy changes, $\tau / \tau^{*}$ must fall, so again the internal price rises in the country that experiences the change in its political environment and falls in the other. In both the export and import cases, an increased government sensitivity to the concerns of special interests in one country raises the profits of the organized factor owners in that country at the expense of their counterparts abroad.

The analysis shows how the domestic political environments color the strategic interactions between countries. We have seen that a decline in the home parameter $a$ induces a change in the foreign country's policy that improves the home country's terms of trade. This

${ }^{18}$ At each point along $P^{*} P^{*}$, the curve is flatter than a ray to that point from the origin. This implies that $\tau * / \tau$ falls as we move out and to the right along the curve. 


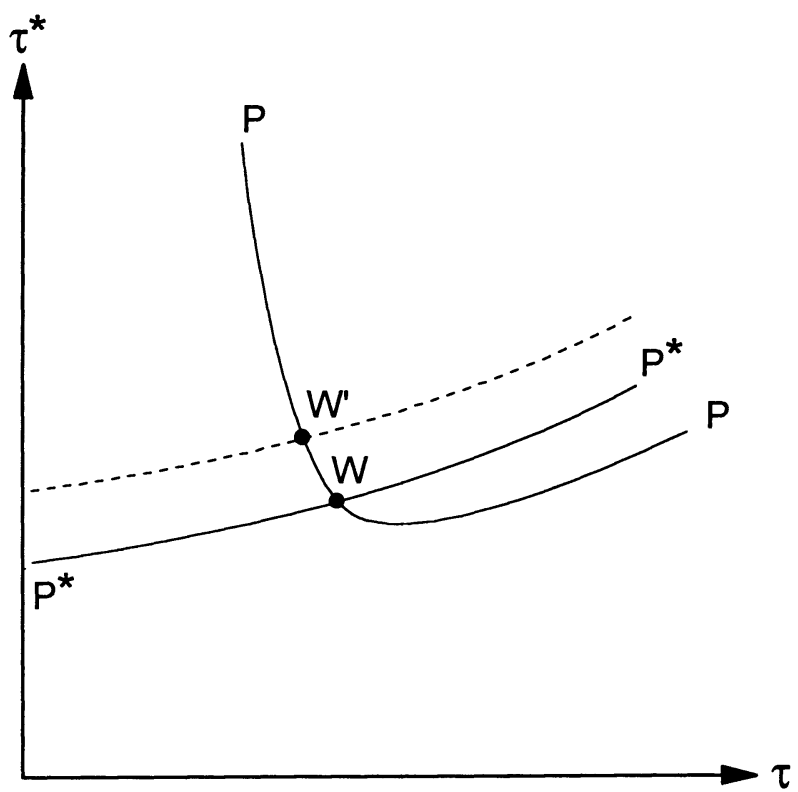

Fig. 2.-Decrease in $a^{*}$

raises the potential for a political paradox: a government that is unresponsive to the public interest might actually serve the general voter well, because the self-interested government can credibly commit to a policy of aggressive support for the domestic industry.

\section{Trade Talks}

We have portrayed the interactions between government officials in different countries who pursue their selfish interests while setting their nations' trade policies. These officials are willing to impose deadweight losses on their constituencies as a means of amassing campaign contributions. Thus the economic inefficiency of the political equilibrium will not be a matter of overriding concern to them. However, there is another sort of inefficiency inherent in the equilibrium of Section IV that may be of greater concern. By choosing their national policies noncooperatively, the incumbent politicians impose avoidable political costs on one another. If the politicians recognize this, they may be willing and indeed anxious to enter into a multilateral trade negotiation. In this section we study equilibria that emerge from trade talks between politically motivated governments.

We allow the two governments to bargain over the trade policy schedules $\tau$ and $\tau^{*}$. For the moment, we also allow them to negotiate 
a transfer payment $R$ (positive or negative) that the foreign country pays to the home country as part of the negotiated agreement. ${ }^{19}$ Some trade pacts such as the European Community's common agricultural policy actually call for such intercountry transfers. However, as we shall see below, the bargaining game has essentially the same equilibrium when $R$ is constrained to zero. Thus our results apply also when transfers are infeasible.

It proves convenient for the exposition to begin with a case in which organized owners of specific factors constitute a negligible fraction of the voters in each country. With $\alpha_{L}=\alpha_{L}^{*}=0$, the members of lobby groups enjoy a negligible share of the surplus from consuming nonnumeraire goods, and they pay a negligible fraction of the head taxes levied by the governments. Thus the interest groups worry only about their factor incomes and the amounts of their political contributions. In the negotiation game, the organized lobbies tie their contributions to the policies that emerge from the international talks; that is, contributions are functions of $\tau$ and $\tau^{*}$. In general, the lobbies might also condition their contributions on the size of the international transfer. But they need not do so here because their members are so few in number that they receive or contribute only a negligible fraction of any payment that is made.

Confronted with the set of contribution schedules $\left\{C_{i}\left(\tau, \tau^{*}\right)\right\}$, the home government comes to the bargaining table with the goal of maximizing

$$
G=\Sigma_{i \in L} C_{i}\left(\boldsymbol{\tau}, \tau^{*}\right)+a\left[W\left(\boldsymbol{\tau}, \boldsymbol{\tau}^{*}\right)+R\right] .
$$

The first term in (19) is the total amount of campaign contributions. The second term represents per capita welfare weighted by the parameter $a$ reflecting the government's concern for the public interest. Notice that the transfer $R$ has been added to the previously defined measure of average gross welfare. This reflects our assumption that transfer payments are combined with any net revenue from trade taxes and subsidies and that the government redistributes the surplus (or collects the shortfall) on an equal per capita basis. The same is true of the foreign government, so its objective becomes

$$
G^{*}=\Sigma_{i \in L^{*}} C_{i}^{*}\left(\boldsymbol{\tau}^{*}, \boldsymbol{\tau}\right)+a^{*}\left[W^{*}\left(\boldsymbol{\tau}^{*}, \boldsymbol{\tau}\right)-R\right] .
$$

For now, we do not commit ourselves to any particular bargaining procedure. Rather we assume only that the politicians settle on an outcome that is efficient from their own selfish perspectives. In other words, we assume that the trade policies that emerge from the negoti-

19 While we allow official, government-to-government transfers, we do not allow side payments (i.e., "kickbacks") from one set of politicians to the other. 
ation are such that $G$ could not be raised without lowering $G^{*}$. The Nash bargaining solution and Rubinstein's (1982) noncooperative bargaining equilibrium, among others, have this efficiency property. Efficiency requires the governments to choose the trade policy vectors to maximize the weighted sum

$$
\begin{aligned}
a^{*} G+a G^{*}= & a^{*} \sum_{i \in L} C_{i}\left(\boldsymbol{\tau}, \boldsymbol{\tau}^{*}\right)+a \Sigma_{i \in L^{*}} C_{i}^{*}\left(\boldsymbol{\tau}^{*}, \boldsymbol{\tau}\right) \\
& +a^{*} a\left[W\left(\boldsymbol{\tau}, \boldsymbol{\tau}^{*}\right)+W^{*}\left(\boldsymbol{\tau}^{*}, \boldsymbol{\tau}\right)\right] .
\end{aligned}
$$

Once this sum has been maximized, the governments can use the international transfer to select (almost) any utility pair $\left(G, G^{*}\right)$ on the straight line defined by (20). ${ }^{20}$

We are now in a position to define an equilibrium in the two-stage game in which lobbies set contribution schedules noncooperatively in the first stage and the governments bargain over trade policies in the second.

Definition 3. An equilibrium trade agreement consists of sets of political contribution functions $\left\{C_{i}^{o}\right\}_{i \in L}$ and $\left\{C_{i}^{* o}\right\}_{i \in L^{*}}$ and a pair of trade policy vectors $\tau^{o}$ and $\tau^{* o}$ such that $(a)$

$$
\begin{aligned}
\left(\boldsymbol{\tau}^{o}, \boldsymbol{\tau}^{* o}\right)= & \underset{\left(\boldsymbol{\tau}, \boldsymbol{\tau}^{*}\right)}{\arg \max } a^{*} \sum_{i \in L} C_{i}^{o}\left(\boldsymbol{\tau}, \boldsymbol{\tau}^{*}\right) \\
& +a \Sigma_{i \in L^{*}} C_{i}^{* o}\left(\boldsymbol{\tau}^{*}, \boldsymbol{\tau}\right)+a^{*} a\left[W\left(\boldsymbol{\tau}, \boldsymbol{\tau}^{*}\right)+W^{*}\left(\boldsymbol{\tau}^{*}, \boldsymbol{\tau}\right)\right] ;
\end{aligned}
$$

(b) for every organized lobby $i \in L$, there does not exist a feasible contribution function $C_{i}\left(\tau, \tau^{*}\right)$ and a pair of trade policy vectors $\left(\tau^{i}\right.$, $\left.\tau^{* i}\right)$ such that (i)

$$
\begin{aligned}
\left(\boldsymbol{\tau}^{i}, \boldsymbol{\tau}^{* i}\right)= & \underset{\left(\boldsymbol{\tau}, \boldsymbol{\tau}^{*}\right)}{\arg \max } a^{*}\left[C_{i}\left(\boldsymbol{\tau}, \boldsymbol{\tau}^{*}\right)+\Sigma_{j \neq i, j \in L} C_{j}^{o}\left(\boldsymbol{\tau}, \boldsymbol{\tau}^{*}\right)\right] \\
& +a \Sigma_{j \in L^{*}} C_{j}^{* o}\left(\boldsymbol{\tau}^{*}, \boldsymbol{\tau}\right)+a^{*} a\left[W\left(\boldsymbol{\tau}, \boldsymbol{\tau}^{*}\right)+W^{*}\left(\boldsymbol{\tau}^{*}, \boldsymbol{\tau}\right)\right]
\end{aligned}
$$

and (ii)

$$
W_{i}\left(\boldsymbol{\tau}^{i}, \boldsymbol{\tau}^{* i}\right)-C_{i}\left(\boldsymbol{\tau}^{i}, \boldsymbol{\tau}^{* i}\right)>W_{i}\left(\boldsymbol{\tau}^{o}, \boldsymbol{\tau}^{* o}\right)-C_{i}^{o}\left(\boldsymbol{\tau}^{o}, \boldsymbol{\tau}^{* o}\right) ;
$$

(c) for every organized lobby $i \in L^{*}$, there does not exist a feasible contribution function $C_{i}^{*}\left(\tau^{*}, \tau\right)$ and a pair of trade policy vectors $\left(\tau^{i}\right.$, $\tau^{* i}$ ) such that (i)

$$
\begin{aligned}
\left(\boldsymbol{\tau}^{i}, \boldsymbol{\tau}^{* i}\right)= & \underset{\left(\boldsymbol{\tau}, \boldsymbol{\tau}^{*}\right)}{\arg \max } a^{*} \sum_{j \in L} C_{j}^{o}\left(\boldsymbol{\tau}, \boldsymbol{\tau}^{*}\right) \\
& +a\left[C_{i}^{*}\left(\boldsymbol{\tau}^{*}, \boldsymbol{\tau}\right)+\Sigma_{j \neq i, j \in L^{*}} C_{j}^{* o}\left(\boldsymbol{\tau}^{*}, \boldsymbol{\tau}\right)\right] \\
& +a^{*} a\left[W\left(\boldsymbol{\tau}, \boldsymbol{\tau}^{*}\right)+W^{*}\left(\boldsymbol{\tau}^{*}, \boldsymbol{\tau}\right)\right]
\end{aligned}
$$

${ }^{20}$ Equation (20) is derived as a weighted sum of (19) and (19*), after $R$ is canceled. The only restriction on feasible $\left(G, G^{*}\right)$ is that neither government can promise to transfer to the other country more than the entirety of the national product. 
and (ii)

$$
W_{i}^{*}\left(\boldsymbol{\tau}^{* i}, \boldsymbol{\tau}^{i}\right)-C_{i}^{*}\left(\boldsymbol{\tau}^{* i}, \boldsymbol{\tau}^{i}\right)>W_{i}^{*}\left(\boldsymbol{\tau}^{* o}, \boldsymbol{\tau}^{o}\right)-C_{i}^{* o}\left(\boldsymbol{\tau}^{* o}, \boldsymbol{\tau}^{o}\right) .
$$

Condition $a$ of the definition stipulates that the settlement is efficient from the point of view of the two negotiating governments. Note that efficiency here means maximization of the joint welfare of the two sets of politicians, not Pareto efficiency for voters. Condition $b$, analogous to the similarly labeled condition of definition 1 , requires that it be impossible for any organized lobby group in the home country to gain by restructuring its contribution schedule, considering that the two governments will settle on a different agreement when one of them faces an altered set of political incentives. The same must be true for organized interest groups in the foreign country, which is the meaning of condition $c$. The equilibrium trade agreement also entails a certain transfer, $R^{o}$, the size of which will depend on the details of the bargaining process.

This two-country game has a structure almost identical to the one that characterizes policy setting in a small country (see Grossman and Helpman 1994). In the case of a small country, the organized lobbies set contribution schedules that induce their common agent (the government) to take a policy action in light of the perceived costs to the agent. The various schedules are set simultaneously, and each constitutes a best response to the others. Here there are two sets of organized lobbies, but still they set their schedules simultaneously and noncooperatively. While there is no identifiable common agent, the objective function in (20) can be interpreted as being that of an "as if" mediator or a surrogate world government. In other words, the equilibrium trade agreement is the same one that would arise if a single decision maker had the preferences given on the right-hand side of (20) and a large set of interest groups constituting the organized lobbies of both countries bid to influence this agent's decisions. Once again, the equilibrium policies can be found by application of lemma 2 in Bernheim and Whinston (1986). That is, we replace conditions $b$ and $c$ of definition 3 by the requirement-analogous to (10) - that the negotiated policy outcome must maximize the joint welfare of each organized lobby and the hypothetical mediator, when the contribution schedules of all other lobbies are taken as given. This requirement can be written as

$$
\begin{aligned}
\left(\boldsymbol{\tau}^{o}, \boldsymbol{\tau}^{* o}\right)= & \underset{\left(\boldsymbol{\tau}, \boldsymbol{\tau}^{*}\right)}{\arg \max } a *\left[W_{j}\left(\boldsymbol{\tau}, \boldsymbol{\tau}^{*}\right)-C_{j}^{o}\left(\boldsymbol{\tau}, \boldsymbol{\tau}^{*}\right)\right] \\
& +a^{*} \sum_{i \in L} C_{i}^{o}\left(\boldsymbol{\tau}, \boldsymbol{\tau}^{*}\right)+a \Sigma_{i \in L^{*}} C_{i}^{* o}\left(\boldsymbol{\tau}^{*}, \boldsymbol{\tau}\right) \\
& +a^{*} a\left[W\left(\boldsymbol{\tau}, \boldsymbol{\tau}^{*}\right)+W^{*}\left(\boldsymbol{\tau}^{*}, \boldsymbol{\tau}\right)\right] \text { for all } j \in L
\end{aligned}
$$


and

$$
\begin{aligned}
\left(\boldsymbol{\tau}^{o}, \boldsymbol{\tau}^{* o}\right)= & \underset{\left(\boldsymbol{\tau}, \boldsymbol{\tau}^{*}\right)}{\arg \max } a\left[W_{j}^{*}\left(\boldsymbol{\tau}^{*}, \boldsymbol{\tau}\right)-C_{j}^{* o}\left(\boldsymbol{\tau}^{*}, \boldsymbol{\tau}\right)\right] \\
& +a \Sigma_{i \in L} C_{i}^{o}\left(\boldsymbol{\tau}, \boldsymbol{\tau}^{*}\right)+a \Sigma_{i \in L^{*}} C_{i}^{* o}\left(\boldsymbol{\tau}^{*}, \boldsymbol{\tau}\right) \\
& +a^{*} a\left[W\left(\boldsymbol{\tau}, \boldsymbol{\tau}^{*}\right)+W^{*}\left(\boldsymbol{\tau}^{*}, \boldsymbol{\tau}\right)\right] \text { for all } j \in L^{*} .
\end{aligned}
$$

Now we introduce the assumption, as we did before, that all contribution schedules are differentiable around the equilibrium point. Then we can make use of the first-order conditions that characterize the solutions to the maximization in condition $a$ of definition 3 and the maximizations in (21) and $\left(21^{*}\right)$. Combining these, we find that the equilibrium contribution schedules again are locally truthful and that the agreed-on policies must satisfy

$$
\begin{gathered}
a^{*} \sum_{i \in L} \nabla_{\tau} W_{i}\left(\boldsymbol{\tau}^{o}, \boldsymbol{\tau}^{* o}\right)+a \Sigma_{i \in L^{*}} \nabla_{\boldsymbol{\tau}} W_{i}^{*}\left(\boldsymbol{\tau}^{* o}, \boldsymbol{\tau}^{o}\right) \\
+a^{*} a\left[\nabla_{\boldsymbol{\tau}} W\left(\boldsymbol{\tau}^{o}, \boldsymbol{\tau}^{* o}\right)+\nabla_{\boldsymbol{\tau}} W^{*}\left(\boldsymbol{\tau}^{* o}, \boldsymbol{\tau}^{o}\right)\right]=0
\end{gathered}
$$

and

$$
\begin{aligned}
& a^{*} \sum_{i \in L} \nabla_{\boldsymbol{\tau}^{*}} W_{i}\left(\boldsymbol{\tau}^{o}, \boldsymbol{\tau}^{* o}\right)+a \Sigma_{i \in L^{*}} \nabla_{\tau^{*}} W_{i}^{*}\left(\boldsymbol{\tau}^{* o}, \boldsymbol{\tau}^{o}\right) \\
& +a^{*} a\left[\nabla_{\tau^{*}} W\left(\boldsymbol{\tau}^{o}, \boldsymbol{\tau}^{* o}\right)+\nabla_{\tau^{*}} W^{*}\left(\boldsymbol{\tau}^{* o}, \boldsymbol{\tau}^{o}\right)\right]=0 .
\end{aligned}
$$

It is straightforward to calculate the partial derivatives in (22) and $(22 *)$. Substituting these expressions, we obtain

$$
\begin{gathered}
a^{*}\left[I_{j L} X_{j}+a\left(\tau_{j}^{o}-1\right) \pi_{j} M_{j}^{\prime}\right]\left(\pi_{j}+\tau_{j}^{o} \pi_{j 1}\right) \\
+a\left[I_{j L}^{*} X_{j}^{*}+a^{*}\left(\tau_{j}^{* o}-1\right) \pi_{j} M_{j}^{* \prime}\right] \tau_{j}^{* o} \pi_{j 1}=0 \quad \text { for } j \in L
\end{gathered}
$$

and

$$
\begin{gathered}
a\left[I_{j L}^{*} X_{j}^{*}+a^{*}\left(\tau_{j}^{* o}-1\right) \pi_{j} M_{j}^{* \prime}\right]\left(\pi_{j}+\tau_{j}^{* o} \pi_{j 2}\right) \\
+a^{*}\left[I_{j L} X_{j}+a\left(\tau_{j}^{o}-1\right) \pi_{j} M_{j}^{\prime}\right] \tau_{j}^{o} \pi_{j 2}=0 \quad \text { for } j \in L^{*} .
\end{gathered}
$$

Equations (23) and $\left(23^{*}\right)$ are two sets of equations that, if independent, might be used to solve for $\tau^{o}$ and $\tau^{* o}$. However, these equations are linearly dependent. ${ }^{21}$ In other words, the equilibrium requirements that we have stated so far determine only the ratios $\tau_{1}^{o} / \tau_{1}^{* o}$, $\tau_{2}^{o} / \tau_{2}^{* o}, \ldots, \tau_{n}^{o} / \tau_{n}^{* o}$, but not $\tau^{o}$ and $\tau^{* o}$ separately. We shall explain the meaning of this finding presently, but first we derive from (23) and $\left(23^{*}\right)$ the following equation that implicitly gives the equilibrium

${ }^{21}$ To establish this, use the properties of the price functions $\pi_{i}(\cdot)$ stated in n. 9 . 
policy ratio in industry $i$ :

$$
\begin{aligned}
\tau_{i}^{o}-\tau_{i}^{* o}= & \left(-\frac{I_{i L}}{a} \frac{X_{i}}{\pi_{i} M_{i}^{\prime}}\right) \\
& -\left(-\frac{I_{i L}^{*}}{a^{*}} \frac{X_{i}^{*}}{\pi_{i} M_{i}^{* \prime}}\right) \text { for } i=1,2, \ldots, n .
\end{aligned}
$$

Notice that when both sides of (24) are divided by $\tau_{i}^{* 0}$, the trade policies enter this equation only in ratio form. ${ }^{22}$

On reflection, it is clear why definition 3-which we have used to characterize an equilibrium trade pact-pins down only the ratio of the two countries' trade policies and not the levels of those policies. The definition stipulates that the equilibrium must be efficient for the two governments without specifying how the surplus will be divided between them. But the ratio $\tau_{i} / \tau_{i}^{*}$ determines the internal prices $p_{i}$ and $p_{i}^{*}$, which in turn determine industry outputs, demands, trade flows, and factor prices in each country. In short, the allocation of resources does not depend separately on $\tau_{i}$ and $\tau_{i}^{*}$, and neither does the joint welfare available to the two sets of politicians. ${ }^{23}$

This brings us to an important point: Equation (24) must characterize the equilibrium trade agreement even if intercountry transfer payments are constrained to be zero. Since allocations do not depend separately on the sizes of the policy wedges in the two countries, the governments can mimic any international transfer payment by increasing (or decreasing) some $\tau_{i}$ and $\tau_{i}^{*}$ while holding their ratio constant. Consider what this would do to trade tax revenue in each country. The revenues that the home country derives from the tax or subsidy in industry $i$ total $r_{i}=\left(\tau_{i}-1\right) \pi_{i} M_{i}$, and those that the foreign country collects amount to $r_{i}^{*}=\left(\tau_{i}^{*}-1\right) \pi_{i} M_{i}^{*}$. An equiproportionate increase in $\tau_{i}$ and $\tau_{i}^{*}$ leaves $\tau_{i} \pi_{i}, \tau_{i}^{*} \pi_{i}, M_{i}$, and $M_{i}^{*}$ unchanged. Therefore, tax receipts must rise in the country that imports good $X_{i}$ and fall in the country that exports this good. Moreover, the offsetting changes in government revenue have exactly the same size. Thus an equiproportionate increase in $\tau_{i}$ and $\tau_{i}^{*}$ is in every way equivalent to a direct transfer from the exporting country to the importing coun-

${ }^{22}$ That is, $X_{i}$ and $M_{i}^{\prime}$ are functions of $p_{i}=\tau_{i} \pi_{i}$, which is homogeneous of degree zero in $\tau_{i}$ and $\tau_{i}^{*}$. Similarly, $X_{i}^{*}$ and $M_{i}^{* \prime}$ are functions of $p_{i}^{*}=\tau_{i}^{*} \pi_{i}$, which is also homogeneous of degree zero in $\tau_{i}$ and $\tau_{i}^{*}$. Finally, the term $\tau_{i}^{*} \pi_{i}$ appears directly in the denominator of both expressions in parentheses, once the equation has been divided through by $\tau_{i}^{*}$. Thus they all can be expressed as functions of the ratio $\tau_{i} / \tau_{i}^{*}$.

${ }^{23}$ Mayer (1981) noted this point in his discussion of efficient bargaining between two aggregate-welfare-maximizing governments. 
try. It follows that a bargain that is efficient when transfers are feasible remains so when they are not. ${ }^{24}$

Recall that we have so far restricted attention to the case in which lobby group members constitute a negligible fraction of the total voting population. We can now extend the analysis to the more general case. When $\alpha_{L} \geq 0$ and $\alpha_{L}^{*} \geq 0$, the following formula applies in place of (24):

$$
\begin{aligned}
\tau_{i}^{o}-\tau_{i}^{* o}= & \left(-\frac{I_{i L}-\alpha_{L}}{a+\alpha_{L}} \frac{X_{i}}{\pi_{i} M_{i}^{\prime}}\right) \\
& -\left(-\frac{I_{i L}^{*}-\alpha_{L}^{*}}{a^{*}+\alpha_{L}^{*}} \frac{X_{i}^{*}}{\pi_{i} M_{i}^{*^{\prime}}}\right) \text { for } i=1,2, \ldots, n .
\end{aligned}
$$

This can be derived in one of two ways. First, we can impose $R=0$ and solve the common agency problem involving lobbies with objectives $v^{i}=W_{i}\left(\boldsymbol{\tau}, \boldsymbol{\tau}^{*}\right)-C_{i}\left(\boldsymbol{\tau}, \boldsymbol{\tau}^{*}\right)$ and $v^{* i}=W_{i}^{*}\left(\boldsymbol{\tau}^{*}, \boldsymbol{\tau}\right)-C_{i}\left(\boldsymbol{\tau}^{*}, \boldsymbol{\tau}\right)$, and a hypothetical mediator who maximizes the right-hand side of (20). The derivation proceeds as before. Alternatively, we can allow $R \neq$ 0 , but then we must permit the lobbies to condition their contributions on the sizes of the transfers obtained by their governments as part of the trade agreement. If we allow for this dependence and write $C_{i}(\cdot)=\tilde{C}_{i}\left(\tau, \tau^{*}\right)+\lambda_{i} R$, and similarly for the foreign lobbies, then we can once again derive (25) as the outcome of the common agency problem. ${ }^{25}$

Equation (25) reveals that, relative to free trade, the negotiated trade agreement favors the industry group that has greater political clout. We have $\tau_{i} / \tau_{i}^{*}>1$ when the first term in parentheses on the right-hand side exceeds the second and $\tau_{i} / \tau_{i}^{*}<1$ when the second exceeds the first. Since $\tau_{i} / \tau_{i}^{*}=1$ in free trade and the home (foreign) domestic price is an increasing (decreasing) function of $\tau_{i} / \tau_{i}^{*}$, it is the

${ }^{24}$ In the event that lobbies can offer contributions to politicians in either country, all campaign giving will be concentrated on the single government that is more easily swayed by such gifts. That is, each industry, no matter where it is located, will offer nothing to the government that places the greater weight on its average voter's welfare and will devote all its efforts to influencing the negotiating position of the government that more readily trades off voter well-being for campaign funds. The upshot is that, instead of (24), the negotiated tariff schedule will satisfy

$$
\tau_{i}^{o}-\tau_{i}^{* o}=\left(-\frac{I_{i L}}{\tilde{a}} \frac{X_{i}}{\pi_{i} M_{i}^{\prime}}\right)-\left(-\frac{I_{i L}^{*}}{\tilde{a}} \frac{X_{i}^{*}}{\pi_{i} M_{i}^{* \prime}}\right) \text { for } i=1,2, \ldots, n,
$$

where $\tilde{a}=\min \left(a, a^{*}\right)$.

${ }^{25}$ We can also show that no lobby can improve its lot by deviating to an arbitrary contribution function $C_{i}\left(\tau, \tau^{*}, R\right)$ in place of the one with the form $\tilde{C}_{i}\left(\tau, \tau^{*}\right)+$ $\lambda_{i} R$. 
politically stronger industry that winds up with greater profits under the agreement as compared to free trade.

Several components enter into the measurement of political power. First and foremost, political power derives from representation in the political process. If the specific factor owners in industry $i$ are organized in one country and not in the other, then the organized group always secures from the trade agreement a gain relative to free trade. When both countries' specific factor owners are organized in some industry, then the more powerful group is the one with the greater stake in the negotiation (i.e., $X_{i}$ vs. $X_{i}^{*}$ ), the one with the government that places less weight on average welfare (i.e., $a$ vs. $a^{*}$ ), and the one in the country in which a smaller fraction of the voting population bids for policies (i.e., $\alpha_{L}$ vs. $\alpha_{L}^{*}$ ). Also, an industry interest group at home gains a political advantage relative to its foreign counterpart if the home import demand or export supply is less price sensitive than that abroad. A high price sensitivity raises the cost to a government of distorting prices and thus makes the government less open to the industry's bids for protection.

When the interest groups in industry $i$ enjoy equal political power in the two countries, a negotiated agreement gives rise to equal rates of import tax and export subsidy. In the event, internal prices, world prices, and industry outputs and profit levels will be the same as in free trade. This finding points to the conclusion that whatever aggregate efficiency losses result from the negotiated trade agreement, they stem not from the mere existence of special-interest politics in the two countries, but from differences in the extent of the political pressures that the interest groups can bring to bear. A trade negotiation pits the powerful lobbies in one country against those in another and thereby neutralizes (to some extent) the power of each one.

Notably absent from the formula in (25) is any measure of the relative market power of the two countries. That is, the foreign trade elasticities - which fully determine the Johnson equilibrium and appear as components of the trade war equilibrium discussed in Section IV - are neglected by the hypothetical mediator of the trade agreement. As is well known, policy-induced terms-of-trade movements benefit one country at the expense of the other and impose a deadweight loss on the world economy. An efficient negotiation will eliminate this source of deadweight loss while perhaps compensating the party that otherwise would have captured the benefits.

It is time now to introduce a specific bargaining procedure in order to show how this determines the division of surplus between the two negotiating parties. For illustrative purposes, we adopt the Rubinstein (1982) bargaining model, as extended by Binmore, Rubinstein, and Wolinsky (1986) and Sutton (1986) to incorporate the risk that negoti- 
ations might break down at any moment when an agreement has not yet been reached.

Suppose that the two governments meet at the bargaining table with the trade war equilibrium of Section IV as the status quo ante. The governments take turns proposing vectors of trade policies $\tau$ and $\tau^{*}$ to replace those in the noncooperative equilibrium. When one government makes an offer, the other can accept or reject. If it accepts, the agreement goes into effect immediately. If it rejects, then a period of time passes during which the policies given in (16) and $\left(16^{*}\right)$ remain in force. At the end of this period the talks may terminate exogenously or else the second government will get an opportunity to make a counterproposal. Termination happens with probability $1-e^{-\beta \Delta}$, where $\Delta$ represents the length of a bargaining period and $\beta$ is a parameter measuring the likelihood of a breakdown per unit of time. The process of alternating proposals continues until either an agreement is reached or a breakdown occurs. In the event of the latter, the noncooperative equilibrium continues indefinitely.

In this setting, there are two costs of failing to reach an immediate agreement. First, the noncooperative equilibrium applies during the bargaining period. Second, the parties face the risk that the talks will come to an end. To capture the cost of delay, we introduce discount rates $\rho$ and $\rho *$ for the two governments. They could arise, for example, if politicians and factor owners have the same discount rates and if the politicians did not collect their promised gifts until after the talks were completed. ${ }^{26}$ The discount rates imply that the home government perceives the value of an agreement reached after $k$ rounds of bargaining to be $e^{-\rho \Delta(k-1)}$ times as great as the value of an agreement with identical provisions that is signed immediately.

In this bargaining game, neither government has an incentive to offer a set of policies when another set would provide strictly greater welfare to both governments. In other words, the offers must maximize the right-hand side of (20). Let the maximal value for this expression be $\bar{G}$. Then we can think of the governments as bargaining directly over the instantaneous welfare levels $G$ and $G^{*}$ subject to the constraint that $a^{*} G+a G^{*}=\bar{G}$. Once a distribution of welfare has been agreed on, the governments can implement the agreement by choosing policies that satisfy (25) and that divide the trade tax revenues as required by the agreement.

We can solve the bargaining game in the manner suggested by Sutton (1986). Let the home country make the first offer, and denote

${ }^{26}$ The governments' discount factors also reflect the fact that the incumbent politicians may not remain in power forever. We view the discount factors as a simple way to capture whatever costs the governments perceive to be associated with delay in reaching an agreement. 
its proposed division of the surplus by $\left(G_{H}, G_{H}^{*}\right)$. Of course the proposal must satisfy

$$
a^{*} G_{H}+a G_{H}^{*}=\bar{G} .
$$

Moreover, the offer will be such as to induce immediate acceptance while leaving the foreign government with no extra surplus relative to what it could achieve by refusing the offer. If the foreign government accepts, it receives $G_{H}^{*}$ forever. If it rejects, the noncooperative equilibrium continues on for a period of at least $\Delta$. Then, with probability $1-e^{-\beta \Delta}$, the negotiations end and the noncooperative equilibrium persists forever; with probability $e^{-\beta \Delta}$, the foreign government gets the opportunity to make a counteroffer, which we denote by $\left(G_{F}\right.$, $\left.G_{F}^{*}\right)$. The foreign government would always choose an offer that would (just) be accepted, so it can count on a flow of utility $G_{F}^{*}$ after the delay of $\Delta$, if the talks do not break down. The home offer that makes the foreign government just indifferent between accepting and rejecting satisfies

$$
\frac{G_{H}^{*}}{\rho^{*}}=\frac{1-e^{-\rho^{* \Delta}}}{\rho^{*}} G_{N}^{*}+\left[\frac{\left(1-e^{-\beta \Delta}\right) e^{-\rho^{* \Delta}}}{\rho^{*}} G_{N}^{*}+\frac{e^{-\beta \Delta} e^{-\rho^{* \Delta}}}{\rho^{*}} G_{F}^{*}\right],
$$

where $G_{N}^{*}$ is the flow of utility to the foreign government in the noncooperative equilibrium of Section IV. The two terms on the right-hand side represent, respectively, the present value of the utility flow during the period before the first possible counteroffer (from time 0 to time $\Delta$ ) and the expected value of the flow from that time onward. Rearranging this equation gives

$$
G_{H}^{*}=\left[1-e^{-\left(\beta+\rho^{*}\right) \Delta}\right] G_{N}^{*}+\left[e^{-\left(\beta+\rho^{*}\right) \Delta}\right] G_{F}^{*} .
$$

We now derive the offer that the foreign government would make were it to reach the stage of counterproposing. The counteroffer $\left(G_{F}, G_{F}^{*}\right)$ satisfies

$$
a^{*} G_{F}+a G_{F}^{*}=\bar{G},
$$

and it provides the home politicians with just enough utility to make them indifferent between accepting the offer and waiting for the chance of still another bargaining round. This indifference condition implies

$$
G_{F}=\left[1-e^{-(\beta+\rho) \Delta}\right] G_{N}+\left[e^{-(\beta+\rho) \Delta}\right] G_{H},
$$

where $G_{N}$ is the flow of utility to the home government in a trade war.

We solve the four equations (26), $\left(26^{*}\right),(27)$, and (28) for the offer $\left(G_{H}, G_{H}^{*}\right)$ and the counteroffer $\left(G_{F}, G_{F}^{*}\right)$. Since the initial offer is 
always accepted, we can readily calculate the division of surplus in the modified Rubinstein game. As is usual in such games, the outcome of the bargaining depends on which government can make the initial offer. However, the advantage from going first disappears as the time between offers shrinks to zero. With continuous bargaining (i.e., $\Delta \rightarrow 0$ ), the equilibrium trade pact yields the following flows of utility to the two governments:

$$
G=\frac{1}{2+\gamma+\gamma^{*}}\left[\frac{1+\gamma^{*}}{a^{*}} \bar{G}+(1+\gamma) G_{N}-\frac{a}{a^{*}}\left(1+\gamma^{*}\right) G_{N}^{*}\right]
$$

and

$$
G^{*}=\frac{1}{2+\gamma+\gamma^{*}}\left[\frac{1+\gamma}{a} \bar{G}+\left(1+\gamma^{*}\right) G_{N}^{*}-\frac{a^{*}}{a}(1+\gamma) G_{N}\right],
$$

where $\gamma=\rho / \beta$ and $\gamma^{*}=\rho^{*} / \beta$. Here, the division of surplus depends on the fallback positions. That is, each government captures more of the gains from cooperation the greater its measure of political welfare in the trade war equilibrium. As usual, higher welfare in the status quo ante gives a negotiator a stronger position at the bargaining table. Each government also gains more from the trade agreement the more patient it can be while bargaining. Patience gives a negotiator a credible threat to decline a low offer, and thus her rival must offer more to ensure an agreement without delay.

\section{Conclusions}

In this paper we have introduced special-interest politics into the analysis of international trade relations. Our model features campaign contributions by industry lobbies that induce policy preferences in self-interested politicians. We have used the model to study policy formation in cooperative and noncooperative international settings.

Our approach rests on the key assumption that interest groups contribute to politicians with the intention of influencing their policy choices. This assumption finds support in the evidence presented by Magelby and Nelson (1990) and Snyder (1990). Moreover, econometric studies of congressional voting behavior suggest that such investments bear fruit. For example, Baldwin (1985) found that a congressperson was more likely to vote against the Trade Act of 1974 the greater the contributions he or she received from major labor unions opposed to the bill; Tosini and Tower (1987) found a positive association between a vote in favor of the protectionist Textile Bill of 1985 and the size of donations received from companies and unions in the textiles and apparel industries. 
When governments set their trade policies noncooperatively, each party neglects the impact of its policies on factor owners and politicians abroad. Our model predicts that in such circumstances higher tariff rates will emerge in industries that are politically organized, all else equal. Rates of protection should vary positively with the stake of the specific factor in trade policy relative to that of the average voter (i.e., with the ratio of output to imports) and inversely with the sizes of the elasticities of foreign export supply and home import demand.

It is difficult to evaluate how well these predictions are borne out by the empirical evidence. While there have been many econometric studies of the determinants of protection across industries, most suffer from a number of serious shortcomings. First, it has been common practice to include a long list of regressors when "explaining" the level of protection in an industry. Often each regressor bears only a loose relationship to some theoretical concept, and different interpretations can be ascribed to the same right-hand-side variable. Second, many of the (collinear) regressors are intended to proxy the same thing, so it is difficult to give meaning to the coefficient on one of them when others are implicitly being held constant. Third, almost all the regressions have been estimated by ordinary least squares, despite the fact that levels of protection clearly influence many of the supposedly exogenous right-hand-side variables. ${ }^{27}$ Finally, none of the studies includes any regressors relating to foreign political and economic conditions, and thus they implicitly assume that international interdependence is unimportant or that foreign industry conditions are uncorrelated with those at home.

With these caveats in mind, the evidence does suggest a positive association between levels of protection and the extent to which an industry is politically organized. Lavergne (1983), Baldwin (1985), and Trefler (1993) have proxied political activism by the economic and geographic concentration of firms, since they presumably affect the ease of organizing politically. These authors find one or both of these variables to be a positive and significant influence on the levels of tariffs or nontariff barriers. As for our prediction that tariffs will be higher in industries with more to gain from protection, the evidence here is ambiguous. Riedel (1977), Baldwin (1985), and others find that protection is higher in industries with greater levels of employment. While consistent with our prediction (more employment means a larger stake, all else equal), this result is difficult to interpret

${ }^{27}$ An exception to this rule is the paper by Trefler (1993), who estimates an equation explaining the level of nontariff barriers jointly with one explaining the pattern of trade. He finds substantial evidence of simultaneity in these two equations. 
because these same authors include the share of labor in value added and the import-penetration ratio as separate explanatory variables. Several studies find that import-penetration ratios are positively related to the level of protection. Our model predicts that the opposite should be true, but again it is difficult to know what the empirical results mean, both because import penetration should really be treated as endogenous and because the regressions hold constant several variables related to the size of the domestic industry. Finally, as for the effects of the elasticities of import demand and export supply, they have not been examined in any of the existing empirical work.

Our model also yields predictions about the outcome of trade negotiations. For example, when governments bargain efficiently, the resulting trade policies for a given industry should not reflect the countries' market power in trade. In other words, the foreign export supply elasticities that should enter into each country's tariff rates in a noncooperative equilibrium should have no bearing on these rates in a cooperative settlement. With international bargaining, rates of protection should reflect not only the political strength of the specialinterest group at home-as indicated by the extent of its political activism, by the ratio of domestic output to net trade, and by the size of the home import demand or export supply-but also the political strength of the interest group in the same industry abroad. Protection should be especially high where the home interest group is strong and the foreign group in the same industry is weak. When both are equally strong, their political influences will cancel, and international prices under a trade agreement should be equal to those that would prevail under totally free trade.

There is some scant evidence that such international bargaining considerations do affect U.S. trade policies. For example, Lavergne (1983) finds that U.S. tariff cuts have been largest in industries in which Canadian producers enjoy the biggest U.S. market share. He interprets this as reflecting the outgrowth of pressures brought by the Canadian government on behalf of its industry interests and the willingness of the U.S. government to concede in the light of corresponding concessions offered U.S. exporters. Still, much remains to be done in testing whether and how the policies prescribed by trade treaties reflect the political pressures that the governments faced when they negotiated the pacts.

\section{References}

Baldwin, Robert E. The Political Economy of U.S. Import Policy. Cambridge, Mass.: MIT Press, 1985.

$\rightarrow$ Becker, Gary S. "A Theory of Competition among Pressure Groups for Political Influence." Q.J.E. 98 (August 1983): 371-400. 
$\rightarrow$ Bernheim, B. Douglas, and Whinston, Michael D. "Menu Auctions, Resource Allocation, and Economic Influence." Q.J.E. 101 (February 1986): 1-31.

$\rightarrow$ Binmore, Ken; Rubinstein, Ariel; and Wolinsky, Asher. "The Nash Bargaining Solution in Economic Modelling.” Rand J. Econ. 17 (Summer 1986): 176-88.

$\rightarrow$ Brock, William A., and Magee, Stephen P. "The Economics of Special Interest Politics: The Case of the Tariff." A.E.R. Papers and Proc. 68 (May 1978): 246-50.

Cowhey, Peter F. "'States' and 'Politics' in American Foreign Economic Policy." In International Trade Policies: Gains from Exchange between Economics and Political Science, edited by John S. Odell and Thomas D. Willett. Ann Arbor: Univ. Michigan Press, 1990.

$\rightarrow$ Fershtman, Chaim, and Judd, Kenneth L. "Equilibrium Incentives in Oligopoly." A.E.R. 77 (December 1987): 927-40.

Findlay, Ronald, and Wellisz, Stanislaw. "Endogenous Tariffs, the Political Economy of Trade Restrictions, and Welfare." In Import Competition and Response, edited by Jagdish N. Bhagwati. Chicago: Univ. Chicago Press (for NBER), 1982.

$\rightarrow$ Grossman, Gene M., and Helpman, Elhanan. "Protection for Sale." A.E.R. 84 (September 1994): 833-50.

$\rightarrow$ Hillman, Arye L. "Declining Industries and Political-Support Protectionist Motives." A.E.R. 72 (December 1982): 1180-87.

Hillman, Arye L., and Moser, Peter. "Trade Liberalization as Politically Optimal Exchange of Market Access." In The New Transatlantic Economy, edited by Matthew Canzoneri et al. Cambridge: Cambridge Univ. Press, 1995.

$\rightarrow$ Johnson, Harry G. "Optimum Tariffs and Retaliation." Rev. Econ. Studies 21, no. 2 (1954): 142-53.

$\rightarrow$ Katz, Michael L. "Game-Playing Agents: Unobservable Contracts as Precommitments." Rand J. Econ. 22 (Autumn 1991): 307-28.

Kennan, John, and Riezman, Raymond. "Do Big Countries Win Tariff Wars?" Internat. Econ. Rev. 29 (February 1988): 81-85.

$\rightarrow$ Kuga, Kiyoshi. "Tariff Retaliation and Policy Equilibrium." J. Internat. Econ. 3 (November 1973): 351-66.

Lavergne, Réal P. The Political Economy of U.S. Tariffs: An Empirical Analysis. Toronto: Academic Press, 1983.

Long, Ngo Van, and Vousden, Neil. "Protectionist Responses and Declining Industries." J. Internat. Econ. 30 (February 1991): 87-103.

Magee, Stephen P.; Brock, William A.; and Young, Leslie. Black Hole Tariffs and Endogenous Policy Theory: Political Economy in General Equilibrium. Cambridge, Mass.: MIT Press, 1989.

Magelby, David B., and Nelson, Candice J. The Money Chase: Congressional Campaign Finance Reform. Washington: Brookings Inst., 1990.

$\rightarrow$ Mayer, Wolfgang. "Theoretical Considerations on Negotiated Tariff Adjustments." Oxford Econ. Papers 33 (March 1981): 135-53.

$\rightarrow$ Peltzman, Sam. "Toward a More General Theory of Regulation." J. Law and Econ. 19 (August 1976): 211-40.

$\rightarrow$ Putnam, Robert D. "Diplomacy and Domestic Politics: The Logic of Two Level Games.” Internat. Organization 42 (Summer 1988): 427-60.

Riedel, James C. "Tariff Concessions in the Kennedy Round and the Structure of Protection in West Germany: An Econometric Assessment." J. Internat. Econ. 7 (May 1977): 133-43.

$\rightarrow$ Riezman, Raymond. "Tariff Retaliation from a Strategic Viewpoint." Southern Econ. J. 48 (January 1982): 583-93. 
$\rightarrow$ Rubinstein, Ariel. "Perfect Equilibrium in a Bargaining Model." Econometrica 50 (January 1982): 97-109.

$\rightarrow$ Snyder, James M., Jr. "Campaign Contributions as Investments: The U.S. House of Representatives, 1980-1986." J.P.E. 98 (December 1990): $1195-1227$.

Stigler, George J. "The Theory of Economic Regulation." Bell J. Econ. and Management Sci. 1 (Spring 1971): 1-21.

$\rightarrow$ Sutton, John. "Non-cooperative Bargaining Theory: An Introduction." Rev. Econ. Studies 53 (October 1986): 709-24.

Tosini, Suzanne C., and Tower, Edward. "The Textile Bill of 1985: The Determinants of Congressional Voting Patterns." Public Choice 54, no. 1 (1987): 19-25.

$\rightarrow$ Trefler, Daniel. "Trade Liberalization and the Theory of Endogenous Protection: An Econometric Study of U.S. Import Policy." J.P.E. 101 (February 1993): 138-60. 